Another problem is the total absence, until recently, of any private sector in the republics of the former Soviet Union with which to interact. Because the scientists have been deprived of such commercial interactions, it is impossible to know with any accuracy the types of projects for which they might be well suited.

Sig Hecker, director of Los Alamos, and John Nuckolls, director of Livermore, visited their Russian counterparts late last month in Arzamas-16 and Chelybinsk70 , which previously had been closed to Western visitors. Two weeks earlier the Americans had played host to the directors of the two Russian laboratories.

Speaking to reporters last week after appearing before a closed committee of the US House of Representatives, Hecker called the Russian weapons laboratories "world-class facilities" with excellent research programmes in such areas as explosively driven high magnetic fields and inertial confinement fusion. But he pointed out that they have no experience in working with the civilian sector and no user facilities of the type common in US laboratories, where many companies conduct proprietary research on expensive machines built by the US government.

At the same time, starting from scratch may have some advantages over operating within a bureaucratic system such as that in the United States. "The disadvantage is that they have no private industry," says Nuckolls about his Russian colleagues. "The advantage is that there are no laws that inhibit such interactions."

The need to keep up the arms race during the Cold War has also shaped the research agenda for scientists in the former Soviet Union. Speaking about the need for research to help clean up a 40-year legacy of environmental problems, Peter Hoffman, a science counsellor in the German Embassy in Washington, says that the weapons scientists "are capable of doing so, but in the past there were political reasons not to do it."

The new centre in Moscow is expected to stimulate this economic conversion by matching Western companies and agencies looking for expertise with Russian research teams looking for encouragement and financing. But business prefers to operate within a stable environment, says D. Allan Bromley, science adviser to President George Bush.

"We must resolve such important issues as ownership and intellectual property rights," Bromley told the US Senate committee at its hearing last week. "Without a structure, our companies will be reluctant to play a role in this exercise."

For all those reasons, then, the attempt by the West to involve Russian weapons scientists in a laundry list of fruitful collaborations may fall short of the mark. But their failure will not be for lack of trying.

Jeffrey Mervis

\title{
Strasbourg project grows
}

\section{London}

THE United States and Britain have agreed for the first time to contribute to the $\mathrm{Hu}$ man Frontier Science Program (HFSP), the largely Japan-financed research organization based in Strasbourg. At the same time, the two-year-old programme has begun a search for a successor to $\mathrm{Sir}$ James Gowans, a British immunologist who will be stepping down as secretarygeneral in March 1993.

HFSP owes its existence to a Japanese proposal at the G-7 meeting of governments of industrialized states at Venice in 1987 for an international attack on the understanding of key issues in biology, and for the exploitation of that knowledge in other fields. First reactions elsewhere were sceptical, chiefly on the grounds that the Japanese proposals were too vague.

But HFSP has now announced the outcome of its third round of research awards. Trustees (comprising two members from each of the G-7 countries, the European Commission and Switzerland) last week approved 37 research grants worth \$24 million over three years, and a further 128 two-year postdoctoral fellowships, each worth $\$ 42,000$ a year.

The budget of HFSP will grow to nearly $\$ 38$ million next year from its current \$31 million, helped by $\$ 3.7$ million from the United States and a British contribution of $£ 350,000$ (US $\$ 600,000$ ). France contributes $\$ 1.6$ million a year, partly as a quid pro quo for the Strasbourg location, apparently influenced by the personal intervention of President François Mitterrand, and Switzerland, Italy and Germany also participate. But Japan remains the major contributor, with close on 80 per cent of the total budget.

It was also agreed last week that Gowans, past secretary of the Medical Research Council, will retire next year after serving four years as secretary-general of the programme. He said he agreed recently to accept a one-year extension of his post, but not to seek reappointment. "I want to get back to my garden", he said.

HFSP's immediate problem is that research applications far outnumber awards. In this year's round, roughly 87 per cent of applications were refused. Gowans says that the only solution is a larger budget.

The ground-rules for the annual competitions specify that research proposals should involve interdisciplinary collaboration between researchers from different member countries. They also must fall in one or other of the two research rubrics, brain function and molecular approaches to problems of biological function such as morphogenesis and energy conversion. Postdoctoral awards are made for work in other member countries.

As in previous years, US researchers seem to have been involved in the greatest number of applications and to have done best in the competition. Nearly a third (12) of the 37 successful applications have group leaders from the United States, while 48 US researchers were involved in the successful applications.

This year, principal applicants from Germany and Japan each secured four awards (out of 29 and 26 applications respectively). France was more successful, with six out of 25 applications, and Britain less so (with two successes in 34

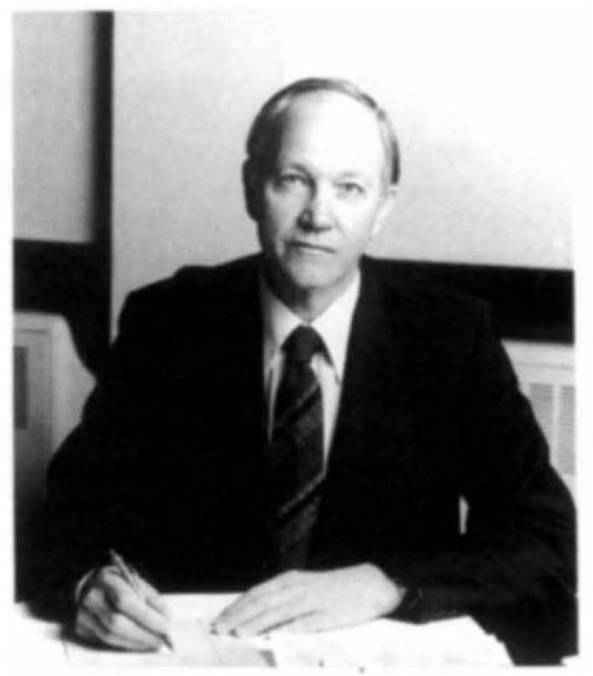

Gowans to stay one more year

applications in which a researcher from Britain was the principal applicant).

Among this year's successful applications is a project to understand the cerebellum. The collaboration will be based at the Brain Research Institute of the University of Zurich and will involve the physics department at the Federal Polytechnic (ETH) and the Electrotechnical Laboratory at Tsukuba. Other projects include a study of the molecular and cellular biology of learning in Drosophila and of Rhizobium nodulation signals in plant development.

HFSP claims that it stands out among international research organizations in its use of genuinely international peer-review panels, themselves appointed by an international scientific council representing member states. The mechanism resembles that used by the now-defunct SCIENCE programme of the European Commission, but is broader in geographical coverage.

One member of the scientific council believes the system of peer review is "unique". J. Edward Rall of the US National Institutes of Health, now the chairman of the council, says that he was originally sceptical of the project, but that he has been "most pleasantly surprised" by the interest and the quality of research grant applications. John Maddox 